\title{
Teacher Feedback and the Acquisition of Simple Past Tense: A Case of EFL Learners
}

\author{
Karim Shabani \\ Allameh Mohaddes Nouri University, Nour, Iran \\ E-mail: shabanikarim@gmail.com \\ Elham Ghasem Dizani (corresponding author) \\ Allameh Mohaddes Nouri University, Nour, Iran \\ E-mail: elhamdizani@gmail.com
}

Received: May 8, 2015 Accepted: June 14, 2015 Published: August 1, 2015

doi:10.5296/jse.v5i3.7771 URL: http://dx.doi.org/10.5296/jse.v5i3.7771

\begin{abstract}
English language teaching has been seeking new ways to teach grammar interactively. The present research looked into the crucial role of interactional feedback and focus on form in the acquisition of simple past tense in speaking tasks within a mixed-method approach. The study was conducted by the participation of 59 upper-intermediate learners between 17 to 30 years of age in 10 treatment sessions in an Iranian EFL (English as a foreign language) context. The learners were assigned into four groups of implicit, explicit, mixed, and control. The number of the structures focused in each interactional group varied, i.e. the implicit group received feedback as simple past, while the explicit was given corrective feedback (CF) on both simple past and past continuous. However, the mixed group dealt with simple past, past continuous, and also pronouns. Findings highlighted the effectiveness of CF since all the interactional groups could outperform the control group, which received no feedback type. Regarding the number of the structures focused, it was found that although implicit group only focused on a single structure, it could not outperform other groups. In other words, both explicit and mixed group performed significantly better than the implicit group in spite of being focused on more than one grammatical point. In sum, it could be inferred from the current study that the kind of feedback given to the learners, i.e. implicit or explicit, can lead to more opportunities of learning rather than being focused on a single structure. Therefore, teachers should provide learners with the correct form wherever possible without considering
\end{abstract}


the number of points corrected in each feedback but by paying attention to the degree of explicitness of the $\mathrm{CF}$ given to the learners.

Keywords: Focus on form, corrective feedback, speaking tasks, interaction 


\section{Introduction}

Interactional feedback has a pivotal role in learning a second and a foreign language since it provides learners with either positive or negative evidence drawing learners' attention to their utterance by comparing their own output with that of a more proficient interlocutor. Some schools of thought like behaviorist and nativist considered errors as sin which hinder communication and must be avoided at all cost (Schulz, 1996) and being corrected immediately if they occurred. Corrective feedback was regarded as something unimportant having no place in classrooms. On the other hand, advocates of interactionist believed positive evidence had a significant role in learning, but negative evidence, which was provided through feedback, was proved to be important as well. There has been a consensus among researchers that explicit attention to form through instruction and corrective feedback particularly in content-and meaning-based L2 (second language) classroom leads to learning (e.g., Lightbown \& Spada, 1990; Muranoi, 2000; Nassaji, 2010). For many years, language teaching was equated to grammar teaching. Long (2000) argues that via focus on forms (i.e. principled selection and presentation of linguistic features and structures in isolated manners) nothing can be gained solely by attempting to teach isolated linguistic forms. However, he believes that some attention to form is essential for language learning, but when it is incorporated into meaning focused activities, it is called as focus on form. Communicative teaching approaches caused negative reactions to teaching grammar among second language teachers. They believed that learners' inability to communicate was because of teaching the grammatical points explicitly. However, recent research in SLA (second language acquisition) has reconsidered the role of grammar instruction.

Later, with the arrival of interaction hypothesis (Long, 1983) and sociocultural theory (Lantolf, 2006) another change has been seen in error correction since both of these theories hypothesized that providing feedback for SLA is essential since on the one hand, it brings about noticing, and on the other hand, it leads to self-regulation. Interactional feedback can occur in two forms: implicit and explicit. The former draws learners' attention implicitly to form through using strategies to negotiate meaning, while the latter draws learners' attention more explicitly through the negotiation of form.

Long (1991, 2000) proposed an approach called FFI (form-focused instruction). Ellis (2001) defined FFI as "any planned or incidental instructional activity that is intended to induce language learners to pay attention to linguistic form", (pp. 1-2). It seems that learners who begin learning when they are beyond early childhood appear to benefit from FFI. According to Fotos (1998), "FonF (focus on form) provides some type of implicit focus on grammar during communicative language teaching", (p.2). In considering the role of attention in SLA, researches have stressed the role of noticing hypothesis as the most common SLA theory regarding the effectiveness of corrective feedback (Schmidt, 1990). This hypothesis (Schmidt, 1990) emphasized the fact that learners are capable of noticing the corrective role of feedback. Both interaction and output hypotheses are closely interwoven with the noticing hypothesis. The interaction hypothesis suggests that "negotiated interaction can facilitate SLA and that one reason for this could be that during interaction, learners may receive feedback on their utterances" (Mackey, Gass, \& McDonough, 2000, p. 471). Based on Swain's output 
hypothesis (1985), output compels learners to move from semantic processing involved in comprehension to syntactic processing needed for production (Nassaji \& Fotos, 2011). Finally, sociocultural theory emphasizes the fact that social interaction and collaborations are two important requirements for learning a language. According to this theory, there is no single type of feedback leading to second language acquisition; instead, acquisition can take place by prompting learners to self-correct and scaffolding their attempts by the employment of corrective strategies that are compatible with learners' developmental level (Aljaafreh \& Lantolf, 1994).

Concerning the immense body of research conducted regarding different feedback types and their usefulness, there is still a need for further research. In this study attempt is made to investigate the effectiveness of interactional feedback, and it is hoped that this study may shed some light on EFL pedagogy in the target setting with upper-intermediate English students in an institute in an EFL context. In order to address the gap in literature, the present study seeks to determine whether interactional feedback will improve learner's speaking through pure speaking tasks by increasing the number of grammatical features in each experimental group, while the main focus is on the acquisition of simple past tense.

\section{Research Questions}

This research aims to respond to the following questions:

RQ1. Does interactional feedback have any effect on the learners' acquisition of simple past tense in the interactional group as a whole in relation to the control group?

RQ2. Do the learners perform better when the target structure is focused or unfocused?

\section{Methodology}

\subsection{Participants}

At the beginning of the study, the sample of the study consisted of 70 Iranian Persian-speaking EFL learners including both male and female between the ages of 17-30 who have been studying English in Kish Air Institute in Chalous, Mazandaran, Iran for over two years. Of the 70 students taking the Oxford Placement Test (OPT), 59 upper-intermediate students were selected in order to take part in this research. Based on the results of the placement tests, the available students were divided into four groups namely explicit, implicit, explicit and implicit (mixed), and control groups.

\subsection{Instrumentation}

In order to answer the first research question, the current study applied semi-structured interview as pre-test, immediate post-test, and delayed post-test to garner adequate data. Two of the speaking tasks, i.e., the picture description and the movie, were presented via computer. For collecting data, pictures presented through the use of computer were used to activate learners' background knowledge and to prepare them for the next task, watching a small part of a movie without hearing anything while watching. Then, they were asked to explain the movie themselves. The 10 treatment sessions were recorded by an MP4 device.

\subsection{Procedure}

The study was conducted within approximately two months including ten sessions of instruction of 40 minutes each for all the groups. After assigning the students into four groups 
according to the results of the placement test, a pre-test was assigned in the form of a semi-structured interview including three questions to elicit the main targeted structure, simple past tense. The required data for the immediate and the delayed post-test were collected in the same way. However, in order to avoid practice effect, the questions varied in the mentioned tests. With respect to the treatments, all the groups were given the same length of treatments (ten sessions of treatment; each lasting about 40 minutes). However, the experimental groups received interactional feedback, while the control group was provided with no form of feedback. Group A (explicit group and unfocused) was given explicit feedback on simple past and past continuous tenses. Group B (implicit group and focused) received implicit feedback on simple past tense. Group C (mixed group and unfocused) dealt with both feedback types and all the target skills namely simple past, past continuous, and pronouns, and group D (control group) that included all the target forms, but received no kind of feedback. All the four groups were taught by the same instructor. All the groups worked on the same speaking tasks every session. The tasks used were in the order of picture description, storytelling (by watching a silent movie and then improvising their own stories), and finally discussion (by talking about their own experiences concerning the topic).

\subsection{Data Analysis}

Based on the research questions formulated in the present study, both qualitative and quantitative methods of data were utilized in the analysis process. To analyze the first research question being the quantitative part of the study, SPSS was employed, while the qualitative data were analyzed by using conversation analysis (CA), which analyzes for important themes related to the research purposes (Wong \& Waring, 2010). With respect to the first research question, an independent sample T-test was applied to make the comparison between the interactional and control groups. All the sessions of treatment, altogether 1200 minutes, were transcribed and then compared by the researchers. The transcriptions were analyzed based on the conversation analysis perspective.

\section{Results}

\subsection{Analysis of First Research Question}

To examine the effects of interactional feedback, the first research question was posed as follows:

'Does interactional feedback have any effect on learners' acquisition of form in the interactional group as a whole against the control group?'

A descriptive analysis of the results of the learners' performance in the experimental or the interactional groups as a whole and that of learners in the control group shows significant differences on the pre- and post-test and delayed post-test. Table 1 shows that learners in the experimental group performed differently on the post-test and on the delayed post-test. There was mean difference between the learners' performance from both groups on the post-test and the delayed post-test. In other words, as can be seen in Table 1, the learners' performance in the interactional group improved significantly from the pre-test $(M=16.9997)$ to the immediate post-test $(M=18.5877)$ and from the pre-test to the delayed post-test (20.5501), while the control group's scores decreased moderately from the pre-test (16.6469) to the immediate post-test (16.5828) and finally to the delayed post-test (16.5116). Thus, the results 
indicate that the instructions were effective for improving learners' oral performance using the targeted structure as there was found a substantial growth in the interactional group's gained scores from the pre-test to the post-tests. Furthermore, the effects of the interactional feedback and focus on form (teaching grammar within interaction) were not only sustained over time but increased substantially.

Table 1. Descriptive statistics for the experimental and the control groups on three occasions

\begin{tabular}{lcclll}
\hline & $\mathrm{N}$ & Minimum & Maximum & Mean & Std. Deviation \\
Interactional pre & 42 & 14.00 & 20.00 & 16.9997 & 1.77766 \\
Interactional post & 42 & 17.00 & 20.00 & 18.5877 & 83196 \\
Interactional delayed & 42 & 18.00 & 81.85 & 20.5501 & 9.71676 \\
Control pre & 17 & 14.67 & 19.33 & 16.6469 & 1.43577 \\
Control post & 17 & 14.33 & 18.33 & 16.5828 & 1.33540 \\
Control delayed & 17 & 14.00 & 18.67 & 16.5116 & 1.50576 \\
Valid N (listwise) & 17 & & & & \\
\hline
\end{tabular}

An independent sample T-test was conducted to see if the students in the interactional group and those in the control group performed differently. According to Table 2, there is a significant difference for the learners in the interactional group $(\mathrm{M}=18.553, \mathrm{SD}=.930)$ and the control group $(\mathrm{M}=16.582, \mathrm{SD}=1.335)(t=.6 .469, p=.000, \mathrm{df}=57)$. The magnitude of the differences in the means (mean difference $=1.97,95 \%$ CI: 2.58 to 2.80 ) was very small (eta squared $=.01)$ 


\section{Macrothink}

Table 2. Result of t-test for the interactional and the control groups on the post-test

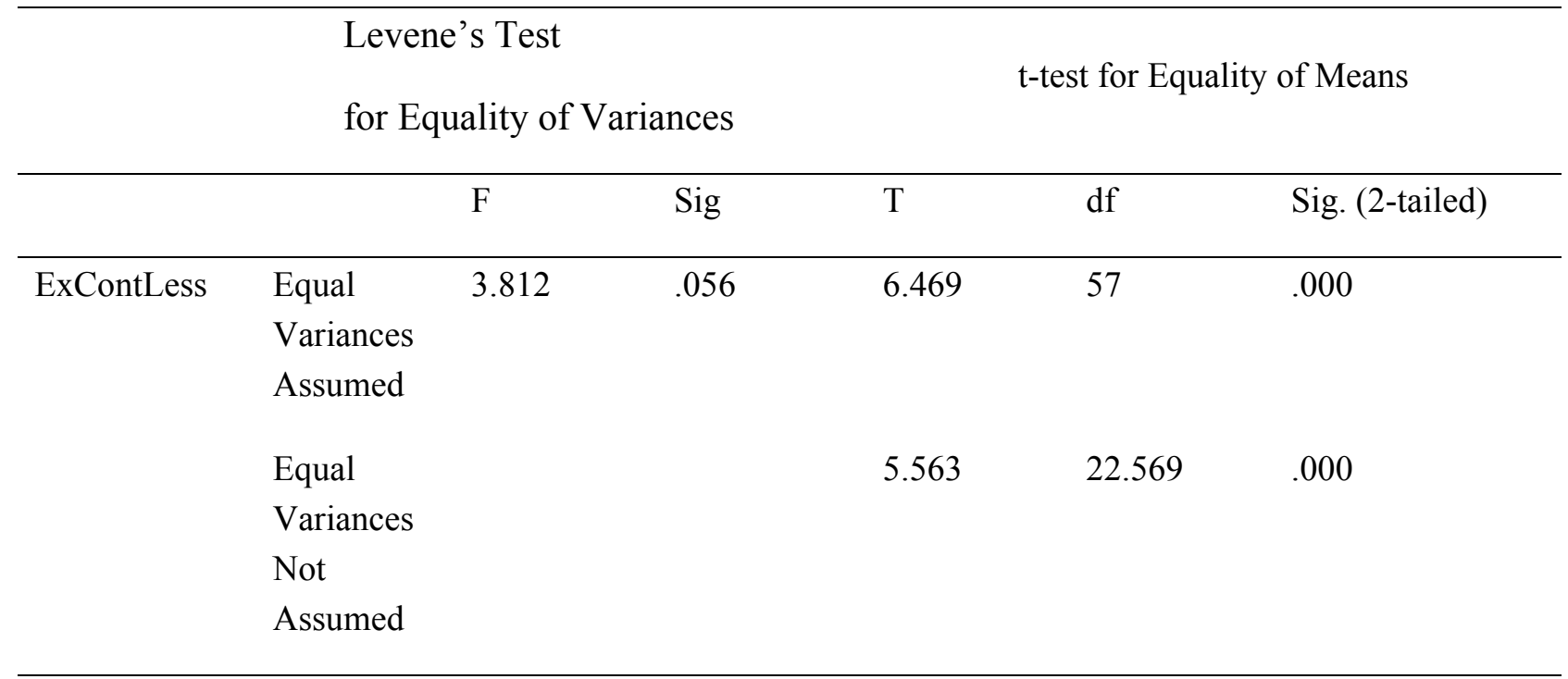

As to the delayed post-test, the result of the independent Sample T-test showed the learners' performance in the interactional group $(\mathrm{M}=20.550, \mathrm{SD}=9.716)$ was significantly better than those in the control group $(\mathrm{M}=16.511, \mathrm{SD}=1.505)(t=1.697, p=.04, \mathrm{df}=57)$. The magnitude of the differences in means (mean difference $=4.038,95 \% \mathrm{CI}: .72$ to 8.80 ) was very small $($ eta squared $=.02)($ see Table 3$)$.

Table 3. Result of t-test for the interactional and the control groups on the delayed post-test

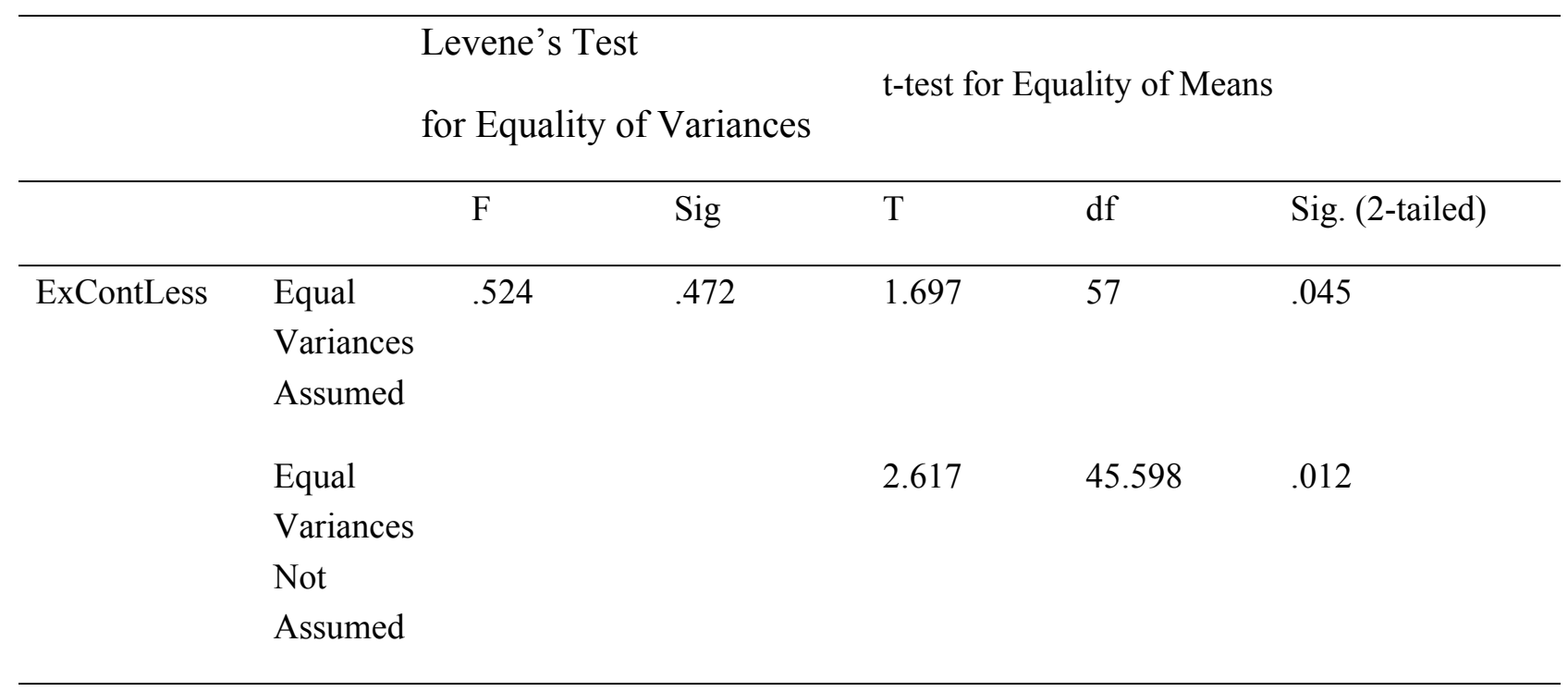

Therefore, it can be concluded from the first research question that interactional feedback and FonF had a great effect on the learners' acquisition of simple past tense.

\subsection{Analysis of Second Research Question}

The second research was 'Do the learners perform better when the target structure is focused or unfocused?' 
It was our aim to examine whether the number of targets had any effects on the learners' noticing of errors and doing the correction. In the implicit group the focus was only on simple past tense, but the number of targets in the explicit group was increased to two grammatical points, simple past and past continuous tenses, and finally the mixed group focused on simple past, past continuous, and pronouns. However, the aim of the study was mainly on the learners' acquisition of simple past tense which was the target of all the groups. The results indicated that in spite of the fact that in the implicit group learners were given feedback just on simple past tense, they could not outperform the other groups, which were not focused on only one target. On the other hand, both explicit and mixed groups significantly outperformed the implicit group; therefore, it can be inferred from the extracts below that the number of target skills that are corrected may not have any effects on the learners' noticing the correct form since in both explicit and mixed groups, it was found that regardless of the number of grammatical structures, the learners' acquisition of the targeted forms had improved during the treatment sessions.

The extract below taken from the implicit group proves the same fact of the ineffectiveness of the number of targets on the learners' performance:

\section{Extract 1.}

S: I have a story about my friend. When she was 5, one boy was fell in love with her. She was very pretty. Until ten years she was 15 . They proposed her, but her father disagree.

\section{$\mathrm{T}$ : oh, he disagreed?}

S: yes, very hard and they didn't accept for $4 / 5$ years. All of people in their town knows/know their story.

T: sorry?

\section{S: know their story}

T: uhuh, all the people knew the story.

S: yes, their love story. Lastly my aunt was agree.

As can be seen in the example above, the learner had several errors and the teacher corrected her each time. However, she could not produce the correct utterance even once. On the other hand, she was not able to notice that she had committed an error. The learner thought that the teacher was interested in the story she was explaining rather than noticing the teacher's feedback to her errors.

In the explicit group, both simple past and past continuous tenses were corrected. The focus was on two target skills; however, learners could recognize them after the teacher had corrected or pointed to the errors. In order to clarify the point, a student and the teacher interaction can be taken into account:

\section{Extract 2.}

T: have you ever had an accident? 
S: yes, twice.

T: oh, my God.

S: yes, it's really bad accident.

$\mathrm{T}$ : it $\mathbf{I S}$ a really bad accident?

S: it was bad accident in a Samand.

T: what were you doing at the time of the accident?

S: I was drive.

T: WAS DRIVE?

S: was driving and the second with a Pride. It happens

\section{T: it HAPPENS?}

S: it happened in Tehran-Chalous.

In the mixed group, learners received correction both on simple past, past continuous, and also pronouns. Although the number of targets was more than the other groups, it did not influence the learners' performance negatively. However, they could respond to corrective feedback positively when they received explicit not implicit feedback like the following extract:

\section{Extract 3.}

S: when I was in dormitory, two person claimed they see a person

T: they CLAIMED they SEE

S: yes.

\section{$\mathrm{T}$ : simple past}

S: saw, saw a person at night. Sometimes they crying

$\mathrm{T}$ : they were crying?

S: was hurrying, was shouting and other students in the other room they call and many of the students went to their room.

T: uhuh, they called them.

S: yes and many of the students went to their room and sometimes my boss went to the room and read/ri:d/ Quran.

T: uhuh, you read/red/ Quran in order to feel peace.

S: yes. 


\section{Macrothink

Here, the learner was provided with several types of feedback. Although in the beginning she could not do the correction by receiving explicit feedback i.e., repetition, which is repeating the learner's utterance using emphatic stress, (Ellis 2009), after receiving metalinguistic feedback, defined as "providing comments, information, or questions related to the well-formedness of the student's utterance", (Lyster 2004, p.405), she could easily correct her error. But, the implicit feedback given to her three times was ignored. After receiving implicit feedback she just confirmed the teacher by saying 'yes', and this 'yes' was not a sign of noticing as she could not perceive the teacher's correction.

In another example, when the learner received a clarification request i.e., indicating you have not understood the speaker's utterance by saying what? Sorry?, (Ellis 2009), which is an implicit type of feedback, she could not notice her error. She just repeated the same utterance as she thought the teacher could not understand what she had said, but by receiving explicit feedback she was easily able to notice her error and do the correction:

\section{Extract 4.}

T: look at the poor boy, he was sobbing. What happened to him?

$\mathrm{S}$ : he is crying for her parents.

\section{T: what?}

$\mathrm{S}$ : he is crying for her parents.

$\mathrm{T}$ : he WAS crying for HIS parents.

S: yes, he was crying for his parents.

As a result, the number of the targets had no effect on the learners' noticing and learning.

\section{Discussion}

\subsection{First Research Question}

As mentioned before, interactional feedback has a pivotal and durable effect on learning a second or foreign language (Ammar \& Spada, 2006; Lyster \& Saito, 2010a, 2010b). The current study focused on using interactional feedback to go for FonF approach. In 1990, Lightbown and Spada stated that when focus on form occurs in a communicative context, it can lead to the learners' improvement of linguistic knowledge and performance. Through focus on form and interactional feedback learners' attention would be drawn on form and noticing can occur according to Schimdt's noticing hypothesis (1990). While previously there was a focus on entirely meaning-centered classrooms, it was later found out that meaning-based instruction could not contribute to the learners' acquisition of linguistic form; thus, there was a need to shift learners' attention from meaning to form in order to be able to gain some accuracy. The current study followed a planned focus on form which is an effective way of calling the learners' attention to form since, as it was mentioned by Ellis, Basturkmen, and Loewen (2002), "it focuses learners repeatedly on the same form while they are communicative. It promotes acquisition" (p. 422). But, these findings and the result of the 
current study are in contrast with what Krashen (1981) argued that conscious attention is not necessary; learning can occur with a little or even no attention. According to him, grammar can be acquired unconsciously through comprehensible input. On the contrary, the current study showed that both focus on form and output are crucial for the acquisition of form.

The present research demonstrated that in the beginning learners were not able to notice the correct form produced by the teacher; however, toward the middle of the treatment sessions, they acquired the ability to not only notice their errors but also do the correction themselves or by their peers. Since the main purpose of communication is understanding; therefore, some errors cause misunderstanding that must be corrected at once otherwise communication cannot occur. CF provides a model for learners by which they can compare their own utterance with that of native speakers or a more proficient speaker. Consequently, they can notice their errors and avoid making the same error. Besides, other students with the same problems may learn from this correction. Thus, $\mathrm{CF}$ is quite effective in learning another language particularly when there is a focus on form.

The learners in the current research outperformed those in the control group since, as time passed, they made fewer errors in comparison with the learners in the control group. The study was in line with Spada and Lightbown (1993) indicating that CF and FonF can positively lead to the learners' development of second language in both short and long term. By following a sociocultural theory, the study revealed that CF leads to acquisition because it acts as a bridge, taking learners from other-regulation to self-regulation (Aljaafreh \& Lantolf, 1994). In the experimental groups, learners were previously dependent on the teacher to give them the correct form, but gradually after some sessions, they gained the ability to do self-correction and even peer-correction. Hence, "CF plays a pivotal role in the kind of scaffolding teachers need to provide to individual learners to promote continued second language growth" (Lyster \& Saito, 2010a, p. 278). The study was also corroborated with studies showing that $\mathrm{CF}$ and FonF are essential elements in learning a second or foreign language (Ammar \& Spada, 2006; Dekeyser, 1993; Loewen, 2004; Lyster, 2004; Nassaji, 2010).

Although the present study found that interactional groups outperformed the control group in both immediate and delayed post-test by receiving CF through entirely communicative tasks by being focused on the acquisition of simple past tense, the difference between the control and experimental groups may be more significant if there were a large number of participants. The study occurred in a different context from previous studies since it was thoroughly communicative. All the tasks used in the research including picture description, storytelling, and discussion, were communicative. However, they all focused on the acquisition of simple past tense speech patterns. In other words, despite the fact that learners were quite aware of simple past tense and its use by being in an upper-intermediate level, they still seemed to have some problems in employing the target structure. Therefore, the current research attempted to provide a challenge for learners by getting them involved in using the structure in an absolutely communicative context because while speaking learners commit more errors particularly if various tasks are used. As a result, it was found out that the communicative tasks and treatment combined with $\mathrm{CF}$ and FonF contributed to the learners' acquisition of 
simple past tense since they made fewer errors through the treatment sessions, and, in the end, they were able to do self-correction, or as it was mentioned in the sociocultural theory, they could move from other-regulation to self-regulation.

\subsection{Second Research Question}

The second research question attempted to figure out whether the number of target structures had any effect on the learners' noticing of simple past tense and their production of the correct form as well. As it was explained in the procedure section, the learners in the implicit group were given feedback on the wrong use of simple past tense. The explicit group was provided with feedback both on simple past and past continuous, and the mixed group received $\mathrm{CF}$ on simple past, past continuous, and pronouns. The purpose was to explore whether being focused or unfocused can have any effects on the learners' acquisition of the main target structure i.e., simple past tense. The results indicated that although learners in the implicit group only received feedback on simple past tense, they could not outperform other groups focusing on more than one grammatical point. In the current research, both the explicit and mixed groups outperformed the implicit group despite the fact that they were not focused on one form; accordingly, the number of target structures had no effect on the learners' acquisition of simple past tense in the current research.

There are a few studies conducted in the area of interactional feedback, which considered the number of target structure that could successfully be managed by the learners. However, these studies revealed that focused correction is more beneficial than unfocused correction (e.g. Ellis, Loewen, \& Erlam, 2006; Lyster, 2004) since, when learners are focused on a single error type, they can notice the error and do the correction more easily. But, the current research showed that no positive effect could be found for the focused group. In other words, as to the extracts given in the results section, it could be understood that the unfocused groups i.e., the explicit and mixed groups, outperformed the focused, the implicit group. The difference found between this research and what Ellis et al (2006) and Lyster (2004) had argued about focused and unfocused correction might be because of the fact that in the present research, the focused group received implicit feedback but the other unfocused groups received explicit feedback with the exception that the mixed group received both implicit and explicit types of feedback and as it was explained and proved previously that explicit feedback is more effective than implicit feedback, the improvements of the unfocused groups in this research could be related to this fact.

The effectiveness and significance of explicit feedback over implicit feedback were also confirmed by the studies conducted by some researchers (Carrol \& Swain, 1993; Ellis et al, 2006; Nassaji, 2009), while there was uncertainty about the effectiveness of recasts i.e., teacher's correction by rephrasing the learners' erroneous utterance (Long, 1996). However, some researchers argued that by making recasts shorter and by using rising intonation, they would be more salient and easier to notice (Chaudron, 1988; Loewen \& Philp, 2006; Nassaji, 2009; Philp, 2003). Regarding recasts, Doughty (2001) stated that when recast is given to learners by being focused on a single or a few features, it can be more effective, but the current research could not reach the same result. In other words, in the implicit group one of 


\section{Macrothink}

the CF types was implicit recasts. The explicit group used explicit recasts, and the mixed group used both implicit and explicit recasts. However, it could not be argued that implicit group, which focused on one grammatical point, could outperform the other groups, but as it was previously explained, the other two groups outperformed the implicit group because in the implicit group, while learners were involved in interaction with the teacher and the other learners in the class, the learners could not perceive the teacher's correction as a focus on form, since by receiving implicit feedback, learners were corrected indirectly. Therefore, they thought that their content contained some errors not their form leading to their attempt to change the content or simply repeat what they had uttered before. For example in the extract below, although the teacher only focused on simple past, the learner did not have the ability to notice her errors. Even though, the correction was done several times, she could not perceive the teacher's intention; hence, being focused in using implicit feedback was not effective in the current research.

\section{Extract 5.}

$\mathrm{T}$ : have you ever felt frightened in life?

S: when I was 13 years old, I was slept and when I woke up at 3 o'clock when at night, I went to.... when I walked to the room, I saw my mom is stand up.

T: sorry?

$\mathrm{S}$ : I saw my mom is stand up.

T: she was standing up and?

S: and when I being near

T: uhuh, when you got closer

S: it's not hidden.

T: Oh, It wasn't hidden.

S: yes, then I cry and shout and go.

$\mathrm{T}$ : what? What were you doing?

S: then I cry and go to my father.

$\mathrm{T}$ : OK, you cried and went to?

S: my father hug and the ghost is hidden.

T: uhuh, the ghost was gone.

S: yes.

On the contrary, in the explicit and mixed group, the learners could perform better though not being focused on a single structure. This can be due to the nature of the feedback provided to 


\section{Macrothink}

the learners. Because of being explicit, they could easily focus on the wrong form and do the correction:

\section{Extract 6.}

S: he left one of his hands like he's falling down.

$\mathrm{T}$ : like he IS falling?

S: like he was falling down, but the girl accept his request.

\section{$\mathrm{T}$ : use simple past.}

S: the girl accepted his request and he came down.

The feedback was given both on simple past and past continuous, but as they were done directly, the learner had no difficulty in observing her error and doing the correction. In the mixed group, learners received feedback on three error types; however, like the explicit group, they could do self-or-peer-correction, but when they received implicit feedback, the error was ignored by the learners as they were not able to grasp teacher's correction. As an illustration, the extract below can be taken into account:

\section{Extract 7.}

T: what about this picture with the vulture. What happened?

$\mathrm{S}$ : the vulture is greedy.

\section{T: sorry? What?}

S: was greedy because of this child.

T: was the boy alive or dead?

$\mathrm{S}$ : he is alive.

T: WAS the boy alive?

S: yes, he was alive, but I think he's crying.

T: why was he crying?

S: he was crying for her family.

\section{T: HER family?}

S: oh, sorry, for his family.

This extract lends support to Lyster and Mori's counterbalance hypothesis (2006), which argues that when teachers use a balanced form of recasts and prompts in classrooms, they may lead to the learners' awareness and acquisition of the target language. Following a sociocultural theory, which argues that a teacher uses a range of various types of feedback in a classroom not just a single CF, it confirms the findings of the current study in which the teacher used different feedback strategies to focus the learners' attention on form particularly 
in the explicit and mixed group. In addition, based on Aljaafreh and Lantolf's (1994) scaffolding technique, feedback must be given to learners step by step in that the teacher is to move from implicit toward explicit feedback because it helps them being scaffolded gradually.

In sum, it can be concluded that the number of target structures did not cause any significant differences on the learners' noticing. In other words, being focused or unfocused did not influence the learners' performance. However, the effectiveness of CF could be related to their degree of explicitness; that is the more explicit, the more noticing and correction. The current research was contrary to the studies carried out regarding focused and unfocused structure because the present research had three experimental groups receiving different types of feedback and worked on different target structures. However, the main factor resulting in no difference between the focused and unfocused groups was the nature of the CF in a way that explicit ones contributed to more noticing and acquisition than the implicit ones.

\section{Conclusion}

Although the undeniable role of corrective feedback has been investigated since teaching came into existence, there is still a need to conduct further research. The current study attempted to investigate the effectiveness of interactional feedback by comparing the experimental groups through three speaking tasks i.e., picture-description, storytelling, and discussion by increasing the number of target structures in each group, including the implicit group focused on simple past, the explicit group on simple past and past continuous, and the mixed group on simple past, past continuous, and pronouns. The findings indicated that interactional feedback might be quite effective for learners, as, according to the quantitative results, all the interactional groups could significantly outperform the control group both in the immediate and delayed post-tests. The second phase of the research investigated whether the number of targets had any effects on learners' noticing and producing the correct form. The findings yielded that although learners in the implicit group were given CF by being focused only on simple past tense, they could not outperform learners in the other groups. In other words, both the explicit and mixed groups that dealt with more than one target structure could perform significantly better than the implicit group.

Several implications emerged from the results. The mixed method used in the current research assisted the researchers to do the comparison among groups thoroughly because the limited number of the participants could not guarantee the significant effect of the interactional feedback if the results were only analyzed quantitatively but with analyzing the results qualitatively, they all could be analyzed in detail based on conversation analysis leading to desirable and more interpretive findings. The focused and unfocused groups employed also provided the researchers with the opportunity to compare the current research with previous studies. Another implication for methodology was its focus on speaking, i.e. the research was entirely oral-based conducted in a communicative setting with the use of interactional tasks. Providing some teacher education courses for both experienced and novice teachers is another implication of the study. 
One of the major pedagogical implications put across by this research is this fact that interactional feedback and FonF structured in a sociocultural framework is a crucial tool in a classroom context. The main theoretical implication proposed by this research was about the role of output. According to Swain's output hypothesis (1985), output has a great role in learning in that it pushes learners to produce the correct form.

The study has several limitations needed to be recognized and considered in future as well. The first and the most important drawback of this research was the limited and small number of participants taking part in this research. Another limitation of this research was the level of the participants and it made it impossible to generalize the findings to other levels of proficiency since the learners were all in upper-intermediate level. Thus, with respect to all these limitations, further research would be required to be directed to study the effects of interactional feedback by comparing different levels of learners in various contexts.

\section{References}

Aljaafreh, A., \& Lantolf, J. P. (1994). Negative feedback as regulation and second language learning in the zone of proximal development. The Modern Language Journal, 78, 465-483. http://dx.doi.org/10.1111/j.1540-4781.1994.tb02064.x

Ammar, A., \& Spada, N. (2006). One size fits all? Recasts, prompts, and L2 learning. Studies in Second Language Acquisition, 28, 543-574. http://dx.doi.org/10.1017/s0272263106060268

Carrol, S., \& Swain, M. (1993). An empirical study of the learning of linguistic generalizations. Studies in Second Language Acquisition, 15, 357-386.

Chaudron, C. (1998). Second language classrooms. Cambridge: Cambridge University Press.

Dekeyser, R. (1993). The effect of error correction on L2 grammar knowledge and oral proficiency. The Modern Language Journal, 77, 501-514. http://dx.doi.org/10.1111/j.1540-4781.1993.tb01999.x

Doughty, C. (2001). Cognitive underpinnings of focus on form. In P. Robinson (Ed.), Cognition and second language instruction (pp. 206-257). New York: Cambridge University Press.

Ellis, R. (2001). Investigating form-focused instruction. Language Learning, 51(Suppl. 1), 1-46.

Ellis, R. (2009). Corrective feedback and teacher development. L2 Journal, 1(1), 3-18.

Ellis, R., Basturkmen, H., \& Loewen, S. (2002). Doing focus on form. System, 30, 419-432.

Ellis, R., Loewen, S., \& Erlam, R. (2006). Implicit and explicit corrective feedback and the acquisition of L2 grammar. Studies in Second Language Acquisition, 28, 339-368.

Fotos, S. (1998). Shifting the focus from forms to form in the EFL classroom. ELT Journal, $52,301-7$. 


\section{$\triangle$ Macrothink}

Krashen, S. (1981).Second language acquisition and second language learning. Oxford: Oxford University Press.

Lantolf, J. P. (2006). Sociocultural theory and L2 State of the art. Studies in Second Language Acquisition, 27, 67-109. http://dx.doi.org/10.1017/s0272263106060037

Lightbown, P., Spada, N. (1990). Focus on form and corrective feedback in communicative language teaching. Studies in Second Language Acquisition, 12, 429-488.

Loewen, S. (2004). Uptake in incidental focus on form in meaning-focused ESL lessons. Language Learning, 54(1), 153-188. http://dx.doi.org/10.1111/j.1467-9922.2004.00251.x

Loewen, S., \& Philp. J. (2006). Recasts in adults English L2 classrooms: Characteristics, explicitness, and effectiveness. The Modern Language Journal, 90, 536-556. http://dx.doi.org/10.1111/j.1540-4781.2006.00465.x

Long, M. (1983). Native speaker/non-native speaker conversation and the negotiation of $\begin{array}{llll}\text { comprehensible } \quad \text { input. Applied } \quad \text { Linguistics, } & \text { 4, }\end{array}$ http://dx.doi.org/10.1093/applin/4.2.126

Long, M. (1991). Focus on form: A design feature in language teaching methodology. In K. DeBot, R. Ginsberge, \& C. Kramsch (Eds.), Foreign language research in crosscultural perspective (pp. 39-52). Amsterdam: John Benjamins.

Long, M. (1996). The role of the linguistic environment in second language acquisition. In W. Ritchie, \& T. Bhatia (Eds.), Handbook of second language acquisition (pp. 413-68). San Diego: Academic Press.

Long, M. (2000). Focus on form in task-based language teaching. In R. D. Lambert \& E. Shohamy (Eds.), Language policy and pedagogy: Essays in honor of A. Ronald Walton (pp. 179-92). Philadelphia, PA: John Benjamins.

Lyster, R. (2004). Differential effects of prompts and recasts in form-focused instruction. Studies in Second Language Acquisition, 26, 399-432. http://dx.doi.org/10.1017/s0272263104263021

Lyster, R., \& Mori, H. (2006). Interactional feedback and instructional counterbalance. Studies in Second Language Acquisition, 28, 269-300. http://dx.doi.org/10.1017/s0272263106060128

Lyster, R., \& Saito, K. (2010a). Interactional feedback as instructional input: A synthesis of classroom SLA research. Language, Interaction, and Acquisition, 1(2), 276-296. http://dx.doi.org/10.1075/lia.1.2.07lys

Lyster, R., \& Saito, K. (2010b). Oral feedback in classroom SLA A meta analysis. Studies in Second Language Acquisition, 32, 265-302. http://dx.doi.org/10.1017/S0272263109990520

Mackey, A., Gass, S., \& McDonough, K. (2000). How do learners perceive interactional feedback? Studies in Second Language Acquisition, 22, 471-497. http://dx.doi.org/10.1017/S0272263100004022 


\section{Macrothink}

Journal of Studies in Education

ISSN 2162-6952

2015, Vol. 5, No. 3

Muranoi, H. (2000). Focus on form through interaction enhancement: integrating formal instruction into a communicative task in EFL classrooms. Language learning, 50(4), 617-673. http://dx.doi.org/10.1111/0023-8333.00142

Nassaji, H. (2009). Effects of recasts and elicitations in dyadic interaction and the role of feedback explicitness. Language Learning, 59(2), 411-452. http://dx.doi.org/10.1111/j.1467-9922.2009.00511.x

Nassaji, H. (2010). The occurrence and effectiveness of spontaneous focus on form in adult ESL classrooms. The Canadian Modern Language Review, 6(6), 907-933. http://dx.doi.org/10.3138/cmlr.66.6.907

Nassaji, H., \& Fotos, S. (2011). Teaching grammar in second language classrooms: Integrating form-focused instruction in communicative context. New York: Routledge, Taylor \& Francis Group.

Philp, J. (2003). Constraints on "noticing the gap" Nonnative speakers' noticing of recasts in NS-NNS interaction. Studies in Second Language Acquisition, 25, 99-126.

Schmidt, R. (1990). The role of consciousness in second language learning. Applied Linguistics, 11(2), 129-158. http://dx.doi.org/10.1093/applin/11.2.129

Schulz, R. (1996). Focus on form in the foreign language classroom: students' and teachers' views on error correction and the role of grammar. Foreign language Annals, 29(3), 343-364. http://dx.doi.org/10.1111/j.1944-9720.1996.tb01247.x

Spada, N., \& Lightbown, P. (1993). Instruction and the development of questions in L2 classrooms. Studies in Second Language Acquisition, 15, 205-224. http://dx.doi.org/10.1017/S0272263100011967

Swain, M. (1985). Communicative competence: Some rules of comprehensible input and comprehensible output in its development. In S. Gass \& C. Madden (Eds.), Input in second language acquisition (pp. 235-53). Rowley, MA: Newbury House.

Wong, J. \& Waring, H. Z. (2010). Conversation analysis and second language pedagogy: A guide for ESL/EFL teachers. New York: Routledge. 